\title{
Patients Body Modeling: A Practical Theoretical Experience in Plastic Surgery
}

\author{
José Humberto Cardoso Resende ${ }^{1^{*}}$ (D), Issacar de Oliveira Costa ${ }^{1}$, \\ Pedro Fernando Huertas Granobles ${ }^{1}$, Rolando Arturo Romero Balcazar', \\ Guilherme Bahia de Carvalho' ${ }^{1}$, Hugo Rojas Perdomo', Edmar Moreira Lisbôa1, \\ Mohamad Youssef Mohsen", Álváro Sanchez Vargas', Nébia Maria Almeida de Figueiredo²
}

${ }^{1}$ UNIREDENTOR University, Rio de Janeiro, Brazil

${ }^{2}$ UNIRIO University, Rio de Janeiro, Brazil

Email: *jresen99@hotmail.com

How to cite this paper: Resende, J.H.C., de Oliveira Costa, I., Granobles, P.F.H., Balcazar, R.A.R., de Carvalho, G.B., Perdomo, H.R., Lisbôa, E.M., Mohsen, M.Y., Vargas, Á.S. and de Figueiredo, N.M.A. (2019) Patients Body Modeling: A Practical Theoretical Experience in Plastic Surgery. Modern Plastic Surgery, 9, 52-58.

https://doi.org/10.4236/mps.2019.93007

Received: May 30, 2019

Accepted: July 28, 2019

Published: July 31, 2019

Copyright (๑) 2019 by author(s) and Scientific Research Publishing Inc. This work is licensed under the Creative Commons Attribution International License (CC BY 4.0).

http://creativecommons.org/licenses/by/4.0/

\begin{abstract}
This research is an active pedagogical experience with surgeons who are specialized in reconstructive plastic surgery and nursing. The guiding questions were the statements of each Surgeon's clients and what they think about them. Modeling the imaginary bodies of the patients and identify what they built in their minds, highlighting topics and the discussion about the practice made in clay modeling. Eight bodies were modeled, with six bodies with all the senses and two incomplete bodies with only the regions of the breasts and buttocks. It was concluded that there are diverse issues emerging such as gender, ethics, care, spirituality and dream as the fulfillment of the wishes of the patients. Where in the body can these surgeons act to improve the patients' physical and quality of life? There is an important theme when we are generally welcoming women into an anamnesis that considers their body as a whole, but what is their expectation for each patient? This paper showed the importance of the preoperative evaluation of this whole, for the indication of repairs or contraindications of procedures that aim to improve the physical of the patients, with possible bodily surgical modifications as a form of modeling through liposuction, grafting or excision with lipectomy and withdrawal of excess skin to mitigate the effects of the transformations that deform the physical and end up harming the human relationship, especially women. This is a qualitative method showing the meanings of the bodies of the women represented in the modeling by the Surgeons. However, some surgeons stand out by the look of their practice, as greater sensitivity looking at the body as a whole, spiritual and emotional. They need to use their skills as surgical art and gift, to try to achieve a means, but not an end.
\end{abstract}




\section{Keywords}

Modeling, Bodies, Surgery, Plastic, Art

\section{Introduction}

We have been working all our professional life operating patients who need surgical repairs in hospitals, with medical faculty and students interested in learning the plastic surgery area. As the world changes, everything around us also changes, as a way of understanding, teaching, and changing the way we do during the post-graduation course of plastic surgery by the Universities. We decided to use an atypical pedagogy, modeling the bodies of patients discussing life, not just the contents that involve teaching. We think that plastic surgeons develop practical and mental skills as they are able to model breasts, abdomen, nose, buttocks, etc. We often model subjectively without realizing how this happens. Often, young plastic surgeons apply a rational practice that marks or removes scars such as tattoos that are difficult to remove, remembering that these surgeons are not always able to achieve the desired result of patients' fantasies or delusions, since most of the time, we only reshape soft bone structures. In cases of birth defects or diseases as the main focus, there is sometimes a body modeling exaggeration for the permanence of eternal youth. As Gabriel Marcel affirms (page 3), there are no limits to the reality of the world. In this sense, the research question focuses on healthy bodies that want to be more perfect as an extension of youth and remaining healthy. At the moment, there is a privileged appreciation of self-centered "beautiful bodies", thinking that plastic surgery can accomplish dreams and bodily miracles. In this paper, the bodies were modeled in clay in the illusion of perfection. We actually try physical practices without considering the psychological, psychosocial, psycho-environmental, and psycho-spiritual dimensions. When thinking, we can fulfill our patients' dreams and desires for a miracle [1]. In Brazil, we currently have around 6083 Plastic Surgeons, considering that modeling images give meaning to what is represented from what surgeons think, but may or may not achieve.

This paper is related to the plastic surgeon's reaction to his patient's body and his attempt to model it in a clay sculpture to reflect, also, his patient's opinion of her own body. The objective is to choose the best surgical technique to meet the patient's expectations, though it is not always possible.

\section{Material and Method}

The qualitative study tries (according to Minaio, 2002) to work with a meaning attributed by the Surgeons to the facts, practical relationships and social phenomena, to interpret the practices and how to model the bodies through surgeries [2]. Portions of clay were distributed in the same amount so each doctor would 
model the bodies of patients of their minds according to their conviction. The modeling was done in the classroom, which we consider as a living laboratory for the development and production of knowledge. The participants were postgraduate doctors with restorative training in Universities and Hospitals. Each doctor had an hour to turn a piece of clay into a body figure of a woman who came into their minds. The results are in Figures 1-7, without identification of the authors, but with the summary of what they thought [3].

Imaginary observations of 8 patients:

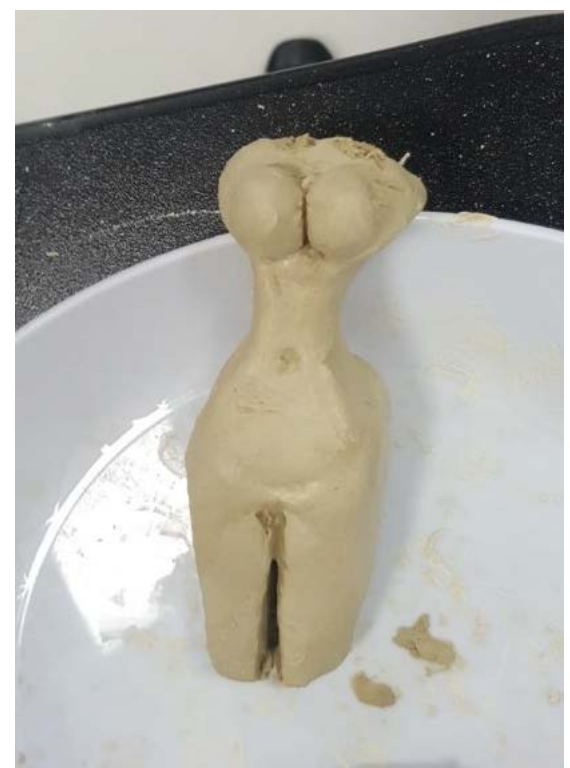

Figure 1. "I saw my patient in the mirror saying that she was horrible, fat and that she wants to keep her body in the form of a guitar, without stretching marks, without marks, and thin."

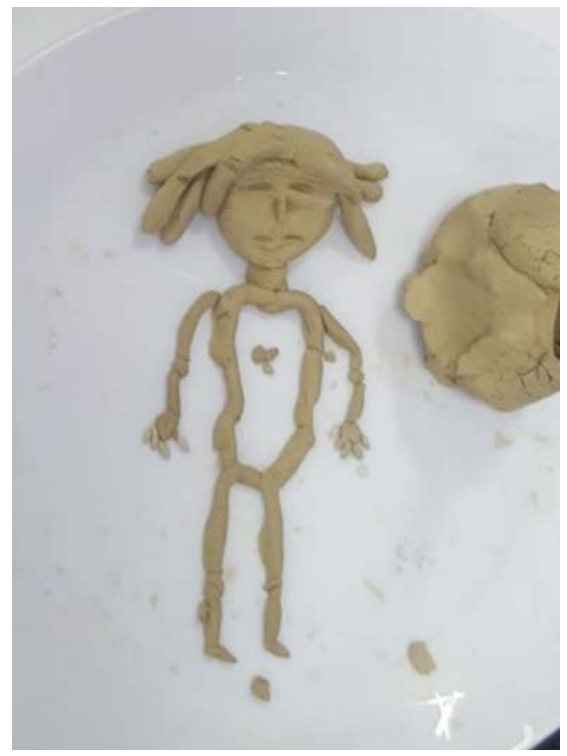

Figure 2. "I heard my patient saying: I want my breasts hard and round, without belly and attractive for my husband." 


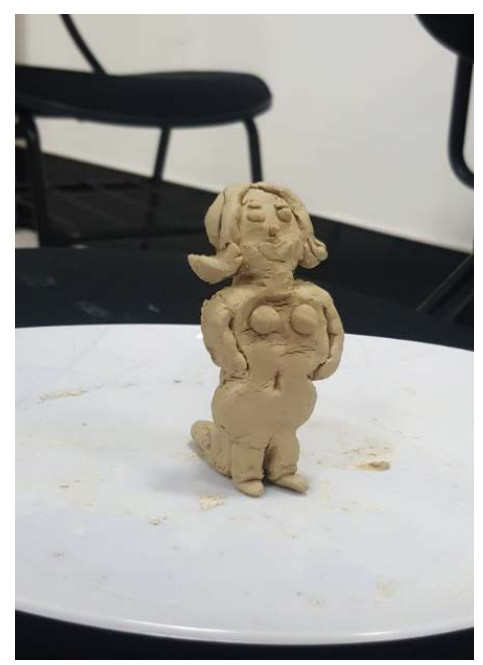

Figure 3. "My patient said, Doctor, it's no use having a pretty face and my body is deformed."

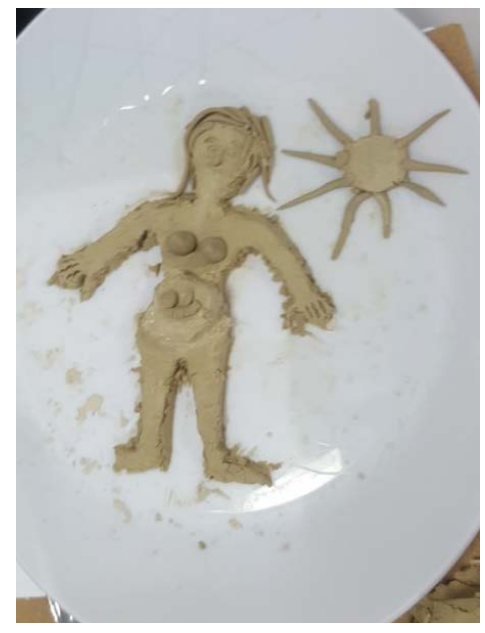

Figure 4. "I heard: 'As my doctor, I would like you to perform a miracle for me to be perfect."”

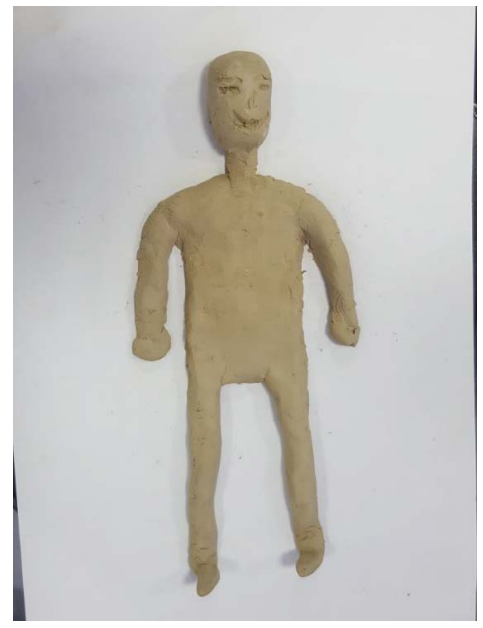

Figure 5. "Doctor: I am here for you to model me, I want the woman's wishes fulfilled so that I have a new quality of life." 


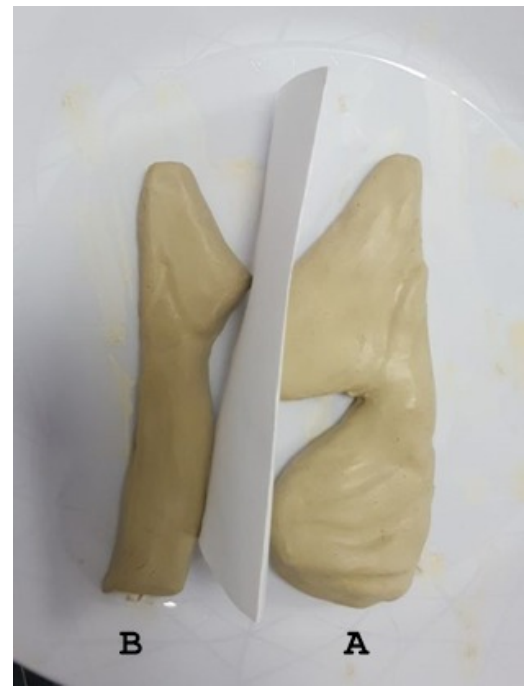

Figure 6. "I thought you could transform me. I keep my feet on the ground, but I consider you a God. I look at my body (A) in the mirror and I wish I had pointed breasts and a well-defined abdomen (B)."

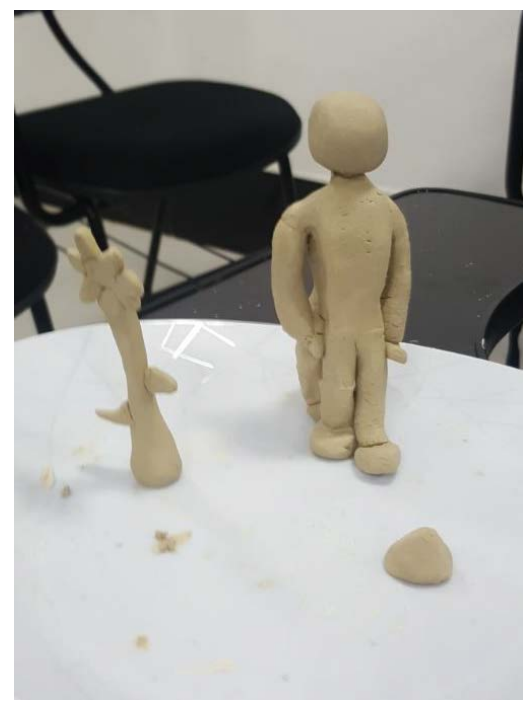

Figure 7. "I would like to be transformed into perfection, but I do not know if you are an artist, I only know that you are a Plastic Surgeon.”

Observation without a figure: "I saw on the Internet that you achieve the impossible, so I saved all my money, but I want to demand perfection.”

Random phrases more heard in doctor's offices:

1) I hate to look at me in the mirror.

2) I feel horrible.

3) I want to have the face of the Italian artist.

4) After I had my children I was deformed.

5) I am saving money to become a guitar.

6) I want to be without marks and thin. 
7) My breasts are crooked, but I want them round without a scar.

8) I want to put my whole body in the right place.

9) I want you to give me what I cannot get with other doctors.

10)I bring this photo, but I want to be like it.

The Organization suggests the dream: The beauty of the body, the wishes of the mind and soul brings the transformational possibility realized by the Surgeon (J. H. Resende, 2016) [4].

\section{Results}

We could divide the results of the study into two parts:

1) The surgeon physician evaluates the client's body such as:

- OK, no corrections needed.

- The breasts are in a pendulum and need to be lifted.

- The breasts are sagged but only with the prostheses corrected.

- The breasts do not need correction but liposuction would be necessary.

- Do the necessary corrections match the wishes of the customers?

- Should I operate this client?

2) Customers evaluate their own bodies, such as:

- I'm horrible!

- I need an urgent plastic surgery.

- How my tits are down!

- Do I want my 45-year-old body just like I was in 18 ?!

- I will break this mirror or make a plastic.

- I want to be beautiful and wonderful!

\section{Analysis and Discussion}

Through this kind of artistic approach (clay modeled bodies) the plastic surgeon exposes his practical reflections on the soul of these bodies. These women, as our patients, whish and dream of a miracle therapy. All this involves sensitivity, subjectivity, talent and good practice with much anticipation [5]. Velloso (2009) said: "It is a social and subjective construction of the body that challenges researchers from different areas of knowledge and also the artists who from the most different languages punctuate the text, engraving, sculpture or cinema that they try to express, interpret it and interpret it on human conditions ..." [6], remembering that not always the dream will be able to come true! Also, the dangers inherent in a surgical act, even with a safe and careful preoperative.

\section{Conclusions}

Within the limit of pages to be published, this study has given us explanations of our knowledge about the body besides plastic surgery. We considered our care, our responsibilities, ethical and aesthetic [7]. It is necessary for these women who wish to undergo plastic surgery to keep "their feet on the ground". Goette said: "Healing without miracles and doing miracles silently." 
The bodies were modeled in clay in this study to bring the illusion of perfection. What is perfection for a deformed body? [8] We conclude that plastic surgery sometimes can't transform a client in their expectations. We advise surgeons to do a pre-operative with explanations about what the client wants and what he can offer. This study is a reflection on the interdependence of factors such as technical knowledge of the plastic surgeon, his natural talent, and the state of each patient, whose body and mental health may cause possible intercurrences, which may affect the final results.

\section{Conflicts of Interest}

The authors declare no conflicts of interest regarding the publication of this paper.

\section{References}

[1] Fontanella, F.C. (1985) The Body on the Threshold of Subjectivity.149f.

[2] Artaud, A. (2013) Le Corps Sans Organes comme critique le Pensee occidental. Revista Entrelinhas, 7, No. 2.

[3] Lins, D. (2000) Antonin Artaud-The Artisan of the Body without Organs. Relume Dunará, Rio de Janeiro.

[4] Resende, J.H.C., et al. (2019) Gigantomastia in Female Workers: "Public Health Cases”. Modern Plastic Surgery, 9, 1-7. https://doi.org/10.4236/mps.2019.91001

[5] Guatari, F. (1992) Chaosmose: A New Aesthetic Paradigm. Brasilian Edition.

[6] de Souza Minayo, M.C. (2002) Ways of Thinking-Epistemology and Method. FioCruz.

[7] Siqueira, D.C.O. (2014) The Body Represented: Media, Art and Production of Meanings. Editora da Universidade do Estado do Rio de Janeiro, Rio de Janeiro.

[8] Velloso, M.P., Rouchou, J. and Oliveira, C. (2009) Body: Identities, Memories and Subjectivities. Mauad X/FAPERJ, Rio de Janeiro. 